\title{
Application Research Based on Ecological Environment and Environmental Protection Technology
}

\author{
Ditong Zhu*, Yingchun Wang ${ }^{1}$ \\ *School of management, Tianjin University of Technology, Tianjin 300384, China, 1084757093@qq.com \\ ${ }^{1}$ School of management, Tianjin University of Technology, Tianjin 300384, China, ycwang@sina.com
}

\begin{abstract}
Ecological environment detection and environmental protection technology becomes an important means to ensure the sustainable development of human beings. Under the premise of the common development of the world's environmental protection, environmental protection is becoming more and more important. Under the background of the development of science and technology, human beings should also fundamentally solve the ecological environmental protection problem. At the same time, multi-domain ecological environment monitoring data will be used to improve the data processing technology capacity to meet the government's multi-source control needs and improve the government's scientific decision-making effect. Starting from the significance of applying ecological environment detection and environmental protection technology, this paper explores and defines the problems existing in the ecological environment detection and environmental protection technology, and puts forward corresponding optimization strategies in combination with big data technology for reference.
\end{abstract}

\section{Introduction}

At present, with the continuous improvement of the level of economic development, while developing the economy, the damage situation to the environment in various regions is extremely severe. Although the state has issued relevant policies and regulatory measures to strengthen environmental supervision and management, there are still some deficiencies, mainly manifested in the following aspects: First, the vegetation is severely damaged and the coverage area is shrinking. With the increasing frequency of industrial and agricultural production activities, in order to promote the development level of industrial and agricultural modernization, various regions have cut down some vegetation, etc., coupled with uneven rainfall throughout the country, the severe drought situation and the destruction of human economic activities, etc., all of which have intensified the rate of vegetation destruction, are not conducive to increasing the coverage rate of vegetation and reducing biodiversity. Second, the situation of land desertification is grim. With the influence of bad weather and vegetation destruction, the soil environment is eroded. Land desertification is especially obvious in some areas, resulting in great economic losses. Third, the reclamation of land, overgrazing and the construction of highway facilities have brought a lot of adverse effects on the above-ground groundwater environment, soil environment, human environment and so on, leading to serious disasters such as soil erosion.

\section{2 ecological technology testing and environmental protection technology application status quo}

\subsection{Lack of perfect management system for testing equipment}

For the application of ecological environment detection and environmental protection technology, it is very necessary to perfect the management system of detection equipment. As the important foundation of the work, the stability of testing equipment determines whether the testing work can be carried out smoothly. Judging from the current actual situation, the management system of domestic testing technology and equipment is not perfect. In the actual ecological environment testing process, there is still the problem of idle equipment, which wastes equipment resources to a certain extent.

\subsection{Lack of funds}

No work can be done without the support of funds, especially in the process of ecological environment detection, the lack of funds will seriously hinder the detection work. Funds are closely related to testing equipment, which is a necessary part of ecological testing ${ }^{[4]}$.At present, domestic testing procedures are not standardized, and Chen's testing equipment is prone to errors in testing data in the actual application process,

\footnotetext{
*Corresponding author: 15630211067@163.com
} 
which affects the smooth progress of ecological testing and the effectiveness and accuracy of testing results.

\subsection{Insufficient awareness of environmental protection and weak professionalism of testing personnel}

Environmental awareness building is a key construction project proposed by global environmental protection organizations in recent years. Judging from the current actual situation, most people do not have sufficient awareness of environmental protection and do not attach importance to environmental protection, so they do not know much about environmental detection and environmental protection technology. In this context, the environmental testing work carried out also has the risk of not conforming to the standards. It is difficult to implement environmental awareness and achieve results in environmental protection work. In addition, the professional knowledge of inspection personnel is to carry out ecological environment inspection and environmental technology, but in fact, many inspection personnel are not of high professional level, it is difficult to combine theory with practice, and it is easy to have problems in inspection work.

\section{Application analysis of ecological environment detection}

\subsection{Biological Detection Technology and Its Application}

With the continuous development of bioengineering, the use of biotechnology is becoming more and more common. Biotechnology is also widely used in environmental detection. Biotechnology is a comprehensive technical system that includes not only basic biology, cell biology, bulk biology, ubiquity, but also biochemistry, computer engineering and environmental engineering. Currently, biotechnology used in environmental detection includes not only macromolecular marker detection but also PCR technology. However, there are different characteristics between the two. For example, biology is characterized by specificity, early warning and practicability. Its main function is to enable biology to interact with the environment and provide relevant theoretical data for environmental management. The main characteristics of PCR technology are fast, sensitive, accurate, simple and highly specific. As PCR is a new technology in recent years, it will play its role in many fields such as life and environment.

\subsection{Physical and Chemical Detection Technology and Its Application}

Due to the complexity and variety of objects for environmental detection. Therefore, physical and chemical technologies can be used in the detection, for example, physical detection can be carried out in the detection of soil, noise pollution, return contamination, etc. However, in the detection of radiation pollution, virus pollution, light and heat, it is inevitable The chemical method is used, and reasonable and effective detection means are adopted in the detection process. It can discover the location and cause of the environmental pollution pavilion accident in time, and analyze the type of pollution, the direction of possible expansion, the cause of pollution, the situation and the degree of pollution, providing a comprehensive, scientific and reasonable theoretical basis for environmental management.

\subsection{S Technology and Its Application}

3S technology mainly includes remote sensing technology (Rs), geographic information system technology (Gs) and global positioning system (GP). It is a comprehensive technology of collection, processing, analysis, expression, management and other aspects. In the process of water resources management, 3S technology can be used not only to detect water resources, but also to evaluate water resources, simulate human culture and ecological changes in river basins, etc.3S technology has applications in water resources. It is also reflected in wetland research, for example, wetland dynamic changes and mapping.Moreover,3S technology is also applied in forest, grassland, farmland and other ecosystems, and plays an important role, such as image inversion when detecting gold in soil.Therefore, $3 \mathrm{~S}$ technology is the most important development object in the future and an important means to improve environmental detection.

\section{4 environmental protection technology application research}

Biological Environmental Protection Technology is an advanced science and technology compared with London at present, and its application in environmental protection projects will show more advantages. For example, with high efficiency, low cost and less pollution, the special advantages of combining biotechnology with environmental protection projects can be embodied in the following two aspects: on the one hand, the ecological environment can be effectively improved so that it will not continue to be terrorized; On the other hand, the operation process is simple and convenient, and the operation method is flexible and changeable. For example, firstly, biological membrane method in biotechnology is widely used in the sewage treatment process, which is mainly to effectively remove soluble and colloidal organic pollutants in wastewater through an ecosystem composed of many high-density microorganisms. Secondly, ecological restoration can be carried out, with good treatment effect, easily an ecosystem composed of many high-density microorganisms. Secondly, ecological restoration can be carried out, with good treatment effect, easily available materials 
and less consumption. Finally, activated sludge method and activated sludge method are aerobic biological treatment methods with sewage as the center, which mainly can effectively purify water resources, and also have good denitrification and removal effect, and are currently the most common users of sewage treatment in cities.

\section{Application of Big Data Processing Technology}

Ecological environment big data technology organically combines all kinds of data and analyzes them to solve complicated ecological environment problems and improve the accuracy and scientificity of enviro nmental decision-making. Through the use of modern ecological environment monitors to collect data and obtain massive data, the ecological environment big data is processed on the basis of cloud computing and other technologies, and then applied in practice to maximize the value of ecological environment big data ${ }^{[2]}$.

\subsection{Big Data Acquisition Technology}

Big data are collected mainly through satellite remote sensing, sensors, radio frequency identification, Internet of Things and mobile platforms. With the improvement of science and technology and the development of informatization, the acquisition methods of ecological environment big data tend to be diversified. The collected data are mainly divided into five categories: ground monitoring data, satellite remote sensing monitoring data, geographic information data, social statistics data and other data (Table 1). The ground weather station monitoring network includes more than 100 data sources and 35,000 weather stations, integrating real-time weather observation data from different countries and regions, and obtaining parameters such as cloud cover, air pressure, wind speed, wind direction, temperature, visibility, precipitation, etc. ${ }^{[1]}$; The global environmental monitoring network mainly covers ecosystem monitoring and environmental pollution monitoring, collecting and analyzing water ecology, terrestrial ecology, environmental quality, nvironmental pollution and the spatio-temporal changes of ecological environment elements ${ }^{[3]}$.

Table 1. Sources and Main Contents of Ecological Environment Big Data Collection

\begin{tabular}{|l|l|}
\hline Category & $\begin{array}{l}\text { Collection sources (Dong Yuhong et } \\
\text { al., 2017) }\end{array}$ \\
\hline $\begin{array}{l}\text { Ground } \\
\text { monitoring data }\end{array}$ & $\begin{array}{l}\text { On-line monitoring system of } \\
\text { ecological environment }\end{array}$ \\
\hline $\begin{array}{l}\text { Satellite remote } \\
\text { data }\end{array}$ & $\begin{array}{l}\text { Remote sensing data, aviation } \\
\text { remote sensing data, etc. }\end{array}$ \\
\hline $\begin{array}{l}\text { Geographic } \\
\text { information data }\end{array}$ & $\begin{array}{l}\text { Remote sensing acquisition, map } \\
\text { digitization, site reconnaissance and }\end{array}$ \\
\hline
\end{tabular}

\begin{tabular}{|l|l|}
\hline & photogrammetry, etc. \\
\hline Social statistics & Statistical departments \\
\hline Web crawlers & Internet, internet of things, etc. \\
\hline
\end{tabular}

\subsection{Overall Structure Design of the Project}

The overall design method of environmental information resource planning mainly adopts the theoretical method of information resource planning (IRP), and excavates, integrates, analyzes and shares environmental data through technologies such as the Internet, the Internet of Things, big data and software platforms. Aiming at the environmental information resource planning and big data analysis application system project, it closely focuses on informatization of various environmental business data, deeply excavates environmental information resources and reasonably develops and applies them. To achieve the scientific, standardized, intelligent and refined management objectives of business work, fully consider the characteristics of ecological environment big data and its development and change laws The overall frame structure is shown in Figure 1.

\begin{tabular}{|c|c|c|}
\hline \multicolumn{3}{|c|}{$\begin{array}{c}\text { The Working Mechanism of Ecological Environment } \\
\text { Big Data Management }\end{array}$} \\
\hline \multirow{4}{*}{$\begin{array}{l}\text { Organiza } \\
\text { tion } \\
\text { Guarant } \\
\text { ee } \\
\text { Standard } \\
\text { and } \\
\text { Standard } \\
\text { System }\end{array}$} & $\begin{array}{l}\text { Big Data Application } \\
\text { Platform }\end{array}$ & \multirow{4}{*}{$\begin{array}{l}\text { Unified } \\
\text { Operatio } \\
\mathrm{n} \text { and } \\
\text { Mainten } \\
\text { ance } \\
\text { Informati } \\
\text { on } \\
\text { Security } \\
\text { System }\end{array}$} \\
\hline & $\begin{array}{c}\text { Big Data Management } \\
\text { Platform }\end{array}$ & \\
\hline & & \\
\hline & Big Data eco-friendly Platform & \\
\hline
\end{tabular}

Fig.1.overall framework diagram of ecological environment (one mechanism, two systems and three platforms)

\section{6 the effective application strategy of ecological environment detection and environmental protection technology}

\subsection{Strengthen capital investment and actively carry out standardized development}

Management process, formulate rules for the use of funds for environmental testing, ensure that the investment of funds can play a practical role in the field of environmental testing, and enable funds to cooperate with the development of testing procedures to meet the national standard ${ }^{[5]}$.

\subsection{Reasonable data analysis, innovative}

Recycling technology to achieve resource regeneration Under the premise of the development of the current big data background, domestic ecological environment detection should adopt flexible methods to use big data, 
and strengthen the detection of the environment through data analysis, so as to provide reliable data basis for the effective implementation of environmental protection technology. We can start with the innovation of recycling technology and devote ourselves to the recycling of real-world resources. For example, for the treatment of primary dyeing of water resources, the sewage can be disinfected and purified according to the analysis of data indexes of water resources purification to ensure the water quality can be recycled, etc.

\section{Conclusion}

At present, the global environmental problem is still very serious, and people's attention to environmental protection is also increasing. Environmental protection has gradually become the focus of China's development. In order to realize the sustainable development of human beings in the future, it is also necessary to continuously strengthen the detection technology of ecological environment, use scientific and effective environmental protection technology, provide real and effective data for environmental governance, and provide factual basis for formulating reasonable and effective environmental protection governance measures in the future, so as to optimize the ecological environment of our country.

\section{References}

1. ZHAO H F, LI R Q, ZHAO F et al, 2018. Curent status and development trend of ecoemxironmental big data[J]. Ecological Science37(1)211-218.

2. JOHNSON A C, DONNACHIE R L, SUMPTER J $P$ et al, 2017.alternative approach to risk rank chemicals on the threat they pose to the aquatic environment $[\mathrm{J}]$. Science of The Total Environment, 599-600; 1372-1381.

3. HU Y. CHENG D, WANG J. et aL.. 2014. Analysis of application satisfaction degree of remote sensing satellites in the field of ecological environment monitoring [j]. Satellite Application (S): 56-64

4. Xia Lanrui. Research on ecological environment detection and environmental protection technology and its application [J]. Environment and Development, 2019(3): 183.

5. An Dong. Brief discussion on ecological environment detection and environmental protection technology [J]. Shanxi Agricultural Economy,2015(6):81 